\title{
Investigating ways to predict channel changes to inform flood risk management now and in the future
}

\author{
Hayley Bowman ${ }^{1}$, Richard Jeffries ${ }^{2}$, Rebecca Ing ${ }^{3}$, Matthew Hemsworth ${ }^{4}$, Natasha Todd-Burley ${ }^{5}$, Barry Hankin ${ }^{6}$, Philip Soar ${ }^{7}$ \\ and Colin Thorne 8 \\ ${ }^{1}$ Environment Agency, Oving Road, Chichester, West Sussex, PO20 2AG, England \\ ${ }^{2}$ Environment Agency, Hafren House, Welshpool Road, Shrewsbury, SY3 8BB, England \\ 3, 4, 5 JBA Consulting, The Library, St. Philip's Courtyard, Church Hill, Coleshill, Warwickshire, B46 3AD, England \\ ${ }^{6}$ JBA Consulting, 1 Broughton Park, Old Lane North, Broughton, Skipton, North Yorkshire, BD23 3FD, England \\ ${ }^{7}$ University of Portsmouth, Winston Churchill Avenue, Portsmouth, Hampshire, PO1 2UP, England \\ ${ }^{8}$ University of Nottingham, University Park, Nottingham, NG7 2RD, England
}

\begin{abstract}
Floods can cause severe and rapid changes in rivers. They can erode river banks and deposit vast quantities of sediment. This can impact on land-use, infrastructure (such as bridges and culverts), and properties where flood risk is increased. Understanding these natural processes, and where they are more likely to occur, can inform risk assessment, and identify opportunities to work with nature. Approaches to identify geomorphological actitivity in rivers have been reviewed to determine which could have potential to create a nationwide assessment of river channel change in England and Wales. Two existing approaches and two novel approaches have been tested and validated against fluvial audits to determine how well they identify geomorphological activity. One of the new approaches developed though the research was used to create a national scenario library of erosion maps representing different sediment sizes, channel roughness, and rainfall probabilities. Such information could be used to plan for future change, prioritise channel maintenance activity to locations with greatest risk or opportunity, and deliver sustainable flood risk and environment management.
\end{abstract}

\section{Channel change in England}

Natural processes of channel change create significant opportunities and issues for the Environment Agency, the environmental and flood risk management authority in England (Environment Agency, 2011).

The Environment Agency spends substantial sums annually on maintaining river channels: between 2015 and 2019 channel maintenance alone amounted to several million pounds per year (Environment Agency, 2014), with more spent on a range of methods of maintaining channel conveyance and form, including bank protection. Other organisations also spend large sums annually on river channel maintenance. This effort manages, and in some cases works against, the work done by natural processes of channel change, such as erosion, sediment transport and deposition.

The factors that control natural processes of channel change are reasonably well understood at the reach scale (e.g. Güneralp et al, 2012) and broadly at the catchment scale (Knighton, 1998). Much channel management work focuses on managing the changes that occur as a relatively gradual incremental process over years to decades when there are few or no extreme flows.

However, channel change can be also be a relatively fast process with major alterations to channel form, activity or location in the space of hours or days when there are extreme flows. In December 2015, extreme rainfall in the north of England (Parry et al., 2015) caused major flooding, leading to changes to the shape and location of many rivers across Cumbria. Flood water entrained large volumes of sediment from channel banks and valley sides, causing landslips and embankment collapse; sediments were deposited downstream, leading to channel widening, avulsion, and aggradation of the channel, causing valley sides and embankments to collapse. Some rivers changed their course (avulsed) to a new location in the floodplain.

Such major physical changes to river channels and their surroundings can be difficult and costly to manage. Disruption can lasts weeks or even months. As an example,

\footnotetext{
${ }^{a}$ Corresponding author: hayley.bowman@environment-agency.gov.uk

DOI 10.3311/FLOODRisk2020.2.26
} 
the widening of the A591 between Grasmere and Keswick in Cumbria ${ }^{\mathrm{a}}$, took 5 months to reopen.

Climate change is predicted to lead to warmer, wetter winters (Watts et al, 2015; 2016) and this is likely to be reflected in alterations to channel processes. An understanding of channel change would therefore be valuable in terms of managing flood risk.

Whilst natural processes of channel change cause flood risk challenges, they also provide opportunities. Natural processes create and maintain important habitats, and underpin healthy, self-sustaining ecological systems that are likely to be more resilient to future changes in climate than artificially constrained, 'brittle' systems (Castro and Thorne, 2019). Understanding the spatial and temporal variation in natural processes therefore lays the foundation for sustainable management of those processes, working with nature, rather than against it, wherever possible.

\section{Information to plan for channel change}

Although channel changes are costly to work with, there is close to no consistent information about how natural channel changes under current conditions, or with predicted climate changes, affect flood risk across England and Wales. Currently there is no national scale information to even understand where erosion or deposition is more likely, in normal or extreme flows.

Fluvial audit data (following the methods outlined in Sear et al., 2003) provides a useful resource, but these do not have national coverage. Anecdotal records and media and social media coverage are also useful. However, to better plan for channel changes and the impacts they may have on flooding, infrastructure and land-use we need to be able to answer the following questions:

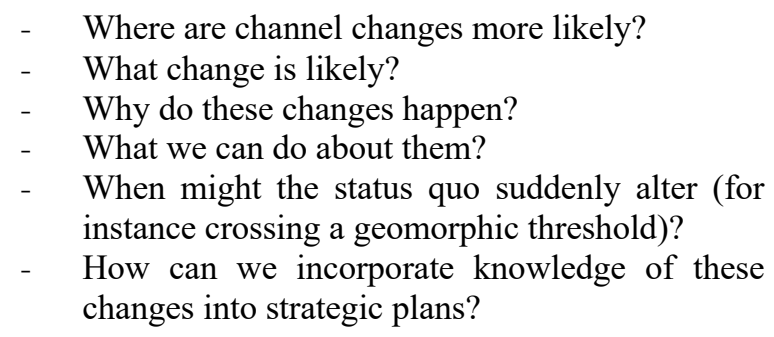

Research was undertaken to investigate approaches that could be applied across England and Wales to identify where river channels are sensitive to geomorphological change (erosion/deposition), aiming to inform flood risk management operational activity.

\section{Identifying approaches to model river channel change}

A literature review identified methods that could be used to understand the potential for erosion and deposition in rivers in England and Wales. Four methods were trialled, which can be broken down into two broad

\footnotetext{
${ }^{a}$ https:/www.gov.uk/government/news/transportsecretary-announces-plans-to-reopen-a591-in-cumbria-
}

categories: stream power approaches and hydrodynamic modelling approaches.

\subsection{Stream power approaches}

Stream power characterises the driving force available for sediment transport. The term stream power was originally used by Bagnold $(1960,1966)$, who defined stream power as the product of the river discharge, slope and weight of water. The capacity of a river to do geomorphological work, i.e. to change the position or morphology of the channel, can be characterised by the availability of stream power to entrain and transport sediment. The following stream power-based approaches were reviewed:

\section{ST:REAM (Parker et al. 2015) \\ Map-derived stream power (Bizzi and Lerner 2015) \\ - $\quad$ REAS (Soar et al. 2017)}

These methods use stream power as an independent variable that affects geomorphic forms and processes such as sediment transport and deposition. These approaches therefore do not account for the feedbacks between form, processes and dynamics.

ST:REAM results are based on the value of the unit width stream power balance (calculated by dividing the unit width stream power of the reach in question by the reach immediately upstream). Threshold values of the unit width stream power balance are used to delineate dominant geomorphological processes for each reach. Threshold values 0.59 and 2.4 are based on research (Parker et al., 2015). Values less than 0.59 are classed as depositional; values between 0.59 and 2.49 are classed as transfer, and values greater than 2.49 are classed as erosional.

\subsection{Hydrodynamic approaches}

Hydrodynamic modelling is a type of simulation using in-channel/floodplain elevation data and hydrograph inflows, where flow varies over time. Industry-standard hydrodynamic software such as HEC-RAS (with a twodimensional hydrodynamic and morphodynamic version in development), Flood Modeller and TUFLOW have sediment / morphology modules and are widely applied for river modelling studies.

Although widely used, the potential to set up and run HEC-RAS, Flood Modeller and TUFLOW models at a national level for modelling sediment processes is presently unfeasible due to the set-up time, data input requirements and model run times.

CAESAR-Lisflood (Coulthard et al. (2013) is a landscape evolution model that combines a hydrodynamic flow model (Lisflood-FP) with a geomorphic model (CAESAR) to simulate erosion and deposition in river catchments and reaches over time scales from hours to 1000 's of years. It can model sediment processes over catchments and has been used in over 60 peer-reviewed

following-storm-desmond-and-eva 
studies across the world (Skinner and Coulthard, 2017), and so was included in the research review.

\subsection{Developing new approaches}

The potential for developing new methods was explored for this project. Two new methods were conceptualised.

The first, the Half-yield method, was developed by Dr Philip Soar (University of Portsmouth, part of JBA Consulting's project team), based on his knowledge of the pitfalls of the existing approaches.

The second, the Shear Stress Data Mining method, was developed by Dr Barry Hankin (JBA Consulting), as a way of using readily-available, but currently under-used, national scale datasets produced from hydraulic models. This is the first time these methods have been published.

\section{The Half-yield method}

The research developed a new approach that is conceptually simple and suitable for employing at the catchment scale for alluvial channels, based on sound theoretical underpinnings related to sediment transport and channel stability.

The Half-yield method was developed to use readily available datasets from River Habitat Surveys (RHS). It does not require a backwater model or require reach delineation. Sites are treated independently of other locations or reaches in the river system to represent an alternative work flow to existing accounting methods based on balances in sediment transport between contiguous reaches.

The proposed conceptual model comprises two stages of assessment: Stage 1, calculating Channel Performance (p) and Stage 2, calculating Channel Effectiveness E).

\subsection{Stage 1: Channel Performance (p)}

The sediment transport capacity of the subject channel is compared with the sediment transport capacity of a theoretical regime channel, according to a CapacityRegime transport ratio (1):

$$
C R R=\frac{Y_{s}}{Y_{r}}
$$

Where $\mathrm{Y}_{\mathrm{s}}=$ sediment yield of the subject channel, based on a representative cross-section for the subject reach; $Y_{r}$ is the sediment yield of the hypothetical regime channel. $Y_{\mathrm{s}}$ and $\mathrm{Y}_{\mathrm{r}}$ are assumed to reflect a period of years (or average annual yield over the long term).

This approach bears similarities to both ST:REAM (Parker et al., 2015) and REAS (Soar et al., 2017) and follows the capacity-supply ratio concept inherent in the methodologies of Soar and Thorne (2001) and Stroth et al. (2017).

Sediment yield, $\mathrm{Y}$, is calculated based on standard magnitude-frequency analysis (Biedenharn et al., 2000; Soar and Thorne, 2011, whereby (2):

$$
Y=\sum_{i=1}^{k}\left(Q s_{i} \times F_{i}\right)
$$

Where $\mathrm{Qs}_{\mathrm{i}}=$ the sediment yield corresponding to class discharge $\mathrm{Q}_{i}$ with decimal frequency of occurrence $\mathrm{F}_{\mathrm{i}}$ (in the flow frequency histogram of k classes).

The theoretical regime channel dimensions are derived based on two assumptions:

i) stable bankfull width conforms to the general form of the downstream hydraulic geometry (regime) equation (3):

$$
W=a Q_{b}^{0.5}
$$

Where $\mathrm{Q}_{\mathrm{b}}=$ bankfull discharge; $\mathrm{a}=$ constant (related to channel type), and

ii) the bankfull discharge equals the half-load discharge, $\mathrm{Q}_{\mathrm{h}}$, in stable alluvial rivers with mobile beds (4):

$$
Q_{b}=Q_{h}
$$

The half load (or half-yield) discharge is a variant of the 'effective discharge', $\mathrm{Q}_{\mathrm{e}}$, derived using standard magnitude-frequency analysis (see Emmett and Wolman, 2001; Vogel et al., 2003; Klonsky and Vogel, 2011; Sholtes and Bledsoe, 2016). Whereas $Q_{e}$ is the 'unique' discharge that transports the most sediment over time, the half-load discharge, $\mathrm{Q}_{\mathrm{h}}$, is the discharge associated with $50 \%$ of the cumulative sediment load $\left(\mathrm{Y}_{50}\right.$, or $\left.\mathrm{C}=0.5\right)$. As $\mathrm{Q}_{\mathrm{h}}$ is measured from the cumulative distribution, it is a more robust measure than the effective discharge and has been found to be a reliable 'process-based' estimator of bankfull discharge in stable river channels (e.g., Sholtes and Bledsoe, 2016).

The assumption, then, is that $\mathrm{Q}_{\mathrm{h}}$ (at $\mathrm{C}=0.5$ ) approximates the bankfull discharge, $\mathrm{Qb}$, in stable alluvial channels with mobile beds (stable in terms of sediment transport continuity and thus channels where their morphologies are 'in regime'). Satisfaction of these criteria (using model iteration) enables the bankfull discharge, regime bankfull width and average bankfull depth to be derived (assuming constant slope).

The quotient $Y_{s} / Y_{r}$ indicates deviation from equilibrium sediment transport, sensitivity to change and thus stable channel morphology, such that $\mathrm{Y}_{\mathrm{s}} / \mathrm{Y}_{\mathrm{r}}>1$ for channels more likely to exhibit erosional behaviour and $0=<\mathrm{Y}_{\mathrm{S}} / \mathrm{Y}_{\mathrm{r}}<1$ for channels more likely to exhibit depositional behaviour. A 'Performance' factor, P, can be defined as:

$$
C R R>1 \quad P=1-C R R
$$

Generating $\mathrm{P}<0$ (erosional behaviour) (5), and

$$
0 \leq C R R<1 \quad P=(1 / C R R)-1
$$

Generating $\mathrm{P}>0$ (depositional behaviour) (6).

Thus, $\mathrm{P}$ takes a value of zero for regime channels where $Y_{s}=Y_{r}$, positive values indicate erosional behaviour and negative values suggest depositional behaviour would predominate. 


\subsection{Stage 2: Channel effectiveness (E)}

Channel 'effectiveness', here, differentiates between the geomorphological performance of in-channel flows and bank overtopping flows and thus provides an indication of the significance of flood flows on the longterm sediment yield. This is achieved by analysing the cumulative sediment yield (decimal contribution to the long-term sediment budget), $\mathrm{C}$.

Where the measured overtopping discharge, $Q_{0}$, corresponds to a value of $\mathrm{C}$ that deviates markedly from 0.5 (at the half load, Y50), this suggests that either flows above or below the overtopping level are predominantly responsible for the total load. Thus, a method that measures how close the overtopping discharge $\mathrm{Q}_{0}$ corresponds to $\mathrm{C}=0.5$ 'might' provide an appropriate guide to the type of flows that are performing the majority of the work in transporting sediment.

An Effectiveness index, E, can be defined as equation (7):

$$
E=1-2 C_{0}
$$

Where $\mathrm{E}(\mathrm{E}:-1<=\mathrm{E}<=1)$ represents the balance between in-channel and overtopping discharges on transporting sediment; $\mathrm{C}_{\mathrm{o}}=$ proportion of the cumulative sediment load ( 0 to 1 ) corresponding to the overtopping discharge.

When $\mathrm{E}=0$ the channel geometry is 'optimised' to convey the imposed sediment load with $50 \%$ of the load transported by within-channel flows and $50 \%$ of the load transported by overbank flows. At this condition, the overtopping discharge, $Q_{0}$ equals the half load discharge $\mathrm{Q}_{\mathrm{h}}$. This does not necessarily mean that the channel is in sediment transporting equilibrium with regime channel geometry.

When $-1<=\mathrm{E}<0$ the majority of the sediment load is conveyed by discharges that do not overtop the banks. This condition suggests that in-channel discharges are responsible for performing most work in transporting sediment and might indicate a channel that is too deep and/or wide for the imposed sediment transport regime. $\mathrm{E}=-1$ for channels that transport all of its sediment by inchannel discharges.

When $0<\mathrm{E}<=1$ the majority of the sediment load is conveyed by discharges that overtop the banks. This condition suggests that overbank discharges are responsible for performing most work in transporting sediment and might indicate a channel that is too shallow and/or narrow for the imposed sediment transport regime or inability to mobilise coarse sediment by low flows. $\mathrm{E}=1$ for channels that transport all of its sediment by overtopping discharges (thus, no discernible channel morphology or armoured bed).

The flow regime might be considered to be balanced (morphologically) if, at the overtopping discharge, E lies between some user-defined threshold, \pm Et (e.g., -0.25 to 0.25 , or -0.5 to 0.5 ).

\section{Shear stress data mining method}

The Shear Stress Data Mining method (SSDM) seeks to make use of existing large scale, high resolution national flood mapping datasets. It used the modelling generated for the Environment Agency Risk of Flooding from Surface Water (RoFSW) maps, which produced detailed $2 \mathrm{~m}$ resolution depth and velocity information with national coverage for a range of probability events $(0.1 \%, 1 \%$ and $3.33 \%$ Annual Exceedance Probability (AEP)).

Depth and velocity grids were produced using a direct rainfall and losses approach (using the Revitalised Hydrograph method after Kjeldson (2007)), whereby net rainfall was estimated in relation to local hydrology, and a 2D flood inundation model, JFlow ${ }^{\circledR}$ (Lamb et al., 2009) was used to route the resulting flows over a $2 \mathrm{~m}$ resolution raster.

The peak depths and velocities were computed through the rainfall event, the accuracy of which is very dependent on the accuracy of the underlying $2 \mathrm{~m}$ merged Digital Terrain Model (DTM) and the representation of the channels and flow accumulation pathways within the DTM. The DTM (2012) comprised $2 \mathrm{~m}$ resolution LIDAR (RMSE $\sim 0.15 \mathrm{~m}$ in the vertical) where available (mainly in urban areas on large rivers), mosaiced into $5 \mathrm{~m}$ Nextmap Britain SAR data (RMSE can be $\sim 1.0 \mathrm{~m}$ in vertical), also resampled to $2 \mathrm{~m}$.

Relatively short duration (1, 3 and 6 hour) summer storm profiles were used over $5 \mathrm{~km}$ tiled domains, and then mosaiced together for each probability to produce the RoFSW probability maps ${ }^{\mathrm{b}}$. This does mean that the summer storm events may not represent the larger flow accumulations associated with flood-critical storms on large fluvial systems, which are typically responsible for the year to year or 'baseline' geomorphic change. This may mean that the model is likely to over-predict on small rivers and under-predict on large rivers. Nonetheless, the events still represent a consistent 'loading' on the system, allowing us to compare shear stresses capable of erosive action on a nation-wide scale for testing purposes.

Shear stress can be derived from a quadratic expression in relation to velocity and Manning's n (Lane and Ferguson, 2005) given in equation (8):

$$
\tau_{0}=\rho g \frac{n^{2}}{d^{1 / 3}} v^{2}
$$

Manning's $n$ is depth dependent, having dimensions $\left[\mathrm{TL}^{-1 / 3}\right]$, so the scaling by $\mathrm{d}^{1 / 3}$ gives the correct dimensions for shear and generates similar values to that of an assumed logarithmic profile. This quadratic equation can then be used and compared against critical shear stress to identify where erosion is more likely.

\footnotetext{
${ }^{\mathrm{b}}$ https://www.gov.uk/government/publications/floodrisk-maps-for-surface-water-how-to-use-the-map
} 
Manning's roughness can be estimated based on land-cover, although for the purposes of initial testing it can be set at a constant value to allow a greater understanding of how the other variables influence shearstress distributions and to avoid sudden changes at boundaries. A fully variable roughness dependent on landcover could be used if the method is taken further.

With an estimate of average depth, depth-averaged velocity and Manning's roughness, and other variables (sediment grain size (D50) and Shields constant (typically between 0.03 and 0.06 )) critical shear stress distribution can be estimated (Komar,1988). Above the critical shear stress local bed material is expected to mobilise. This was used to define zones where erosion would be expected in river channels and across the floodplain where flow routes were present in the depth and velocity maps.

A deposition factor was introduced to define zones where deposition is expected. This was assumed to be at $30 \%$ of the critical shear, below which most material present will not be mobile. The deposition factor helps to distinguish between zones where most material will remain on the bed for a given flow.

The zone between erosion and deposition has been called 'transition', in which smaller grain sizes present may also be mobilised, or larger sediments presents may be settling.

Overall, this produces a zonal classification of sediment erosion, transition and deposition, which can be computed for a range of assumptions, although much of the focus in the trial completed is on the zones of erosion.

Having this information for the three annual exceedance probabilities could allow banding of zones of erosion as high, medium or low probability in a similar way to how the surface water maps are presented and interpreted.

The SSDM approach used here relies on an efficient ArcGIS model builder code that computes local shear based on average velocity, depth and roughness. This is compared with critical shear stress for entrainment and erosion, using three assumptions on deposition, erosion and sediment grain size distribution.

Similar approaches have been used based on re-using 2D modelling outputs, with validation against field data (Reid et al.,2018), and the use of physics-based formulations of erosion potential has been used for some time (e.g. Lane et al., 2005). The Reid et al. 2018 paper showed the utility of a similar shear-stress based approach (derived from 2D model outputs) for understanding gravel bar evolution when combined and compared with very high resolution terrestrial LIDAR.

\section{Testing and validating approaches}

The various approaches were assessed based on their potential for application at a national scale, their strengths and weaknesses, along with consideration of whether climate change is (or could be) factored into the method.

Multi-criteria analysis was developed and used to select four methods to further analyse in catchment trials:
ST:REAM; CAESAR-Lisflood; the Half-yield method; and the Shear Stress Data Mining method.

Three English river catchments were selected that exhibit different hydromorphological processes and environmental settings, and had available data to test the approaches. These were the River Kent (Cumbria), the River Stour (Dorset) and the River Wharfe (North Yorkshire).

The River Kent is in Cumbria, England and originates in the hills surrounding Kentmere, passing through the town of Kendal, before flowing into the north of Morecambe Bay. It was chosen as a typical example of an energetic upland catchment. It experienced flooding in 2005, 2009 and in winter 2015/16.

The River Wharfe in North Yorkshire drains the east side of the Pennines. It was chosen as an example of a system that drains higher ground onto a lower energy alluvial system.

The River Stour in Dorset was chosen as an example of a lower energy system with a mixture of clay and chalk geology, and was more typical of conditions across large areas of lowland England.

\subsection{Developing catchment models}

Step-by-step method workflows were produced for all methods and followed to produce results in the trial catchments.

To work effectively within the project contract and timescales, not all methods could be trialled in all catchments. ST:REAM and Half-yield models were developed for all three catchments. CAESAR-Lisflood, a more resource intensive method, was only applied in the River Kent catchment. The Shear Stress Data Mining uses national datasets and initial zones were produced for two example AEP Surface Water maps corresponding to 3.33 $\%$ and $1 \%$ AEP and specific variables (Manning's roughness of 0.05 , D50 of 50mm and Shields constant 0.6 ) for England and Wales.

\subsection{Validating results}

The model results were validated against fluvial audits and aerial photography. All methods were trialled in the Kent catchment. Here, ST:REAM has a $60 \%$ agreement rate between the fluvial audit data and the model results. CAESAR-Lisflood and the Half-yield method have a $50 \%$ and $40 \%$ agreement rate respectively.

The agreement rate calculation for the Half-yield method depends on the availability of RHS data points (i.e. if an RHS point is not available at the spot check validation point the result is recorded as a 'negative match'). If these spot checks with missing RHS data are excluded from the calculation, the agreement rate for the Half-yield method increases to $80 \%$. This highlights that although the method performs well in terms of identifying geomorphological processes at a reach scale, its utility is highly dependent on the availability of RHS data, which will ultimately limit its ability to provide national scale coverage.

For the Stour and Wharfe catchments, the Half-yield method identifies geomorphological processes with a $38 \%$ 
and $50 \%$ agreement rate respectively between the fluvial audit data and the model results (including spot check locations with missing RHS data points).

In comparison, ST:REAM performs less well in the Stour and Wharfe catchments, with only a $13 \%$ and $38 \%$ respective agreement rate between the fluvial audit data and model results.

The Shear Stress Data Mining method predicted geomorphological processes reasonably well when compared to fluvial audit data and aerial imagery in the Kent, Stour and Wharfe catchments. The spot check comparisons showed a good correlation with audit data at a fine resolution $(2 \mathrm{~m})$, whilst the outputs also corroborated data at the reach-scale and valley scale. There was reduced accuracy of model outputs in areas of tree cover, as well as within lower catchment reaches.

For illustrative purposes images of the modelled method outputs are shown in in Figures 2 to 5, with a description of how each model's outputs compare with the River Kent fluvial audit (Figure 1).

In the location shown in Figure 1, the River Kent channel is confined, embanked, over wide and walled with no floodplain connectivity. There are several weirs and bridges. As a result of the artificial channel environment, extensive deposition of the bed occurs.

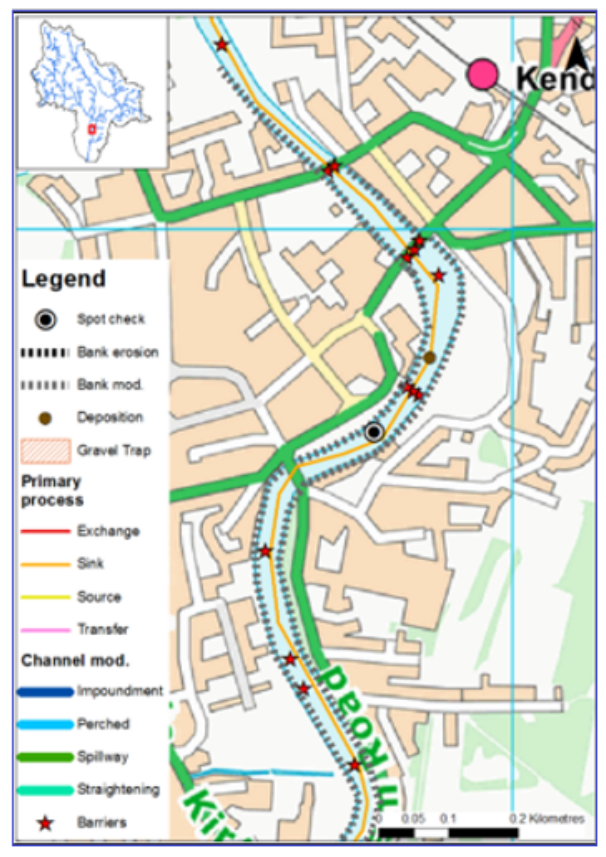

Figure 1. Fluvial audit results of the River Kent near Kendal

Figure 2 shows the ST:REAM results for the River Kent. Values with a capacity supply ratio lower than 0.59 are classed as depositional; values between 0.59 and 2.49 are classed as transfer; and values greater than 2.59 are classed as erosional. The modelled results here show a depositional reach, which matched well to the fluvial audit.

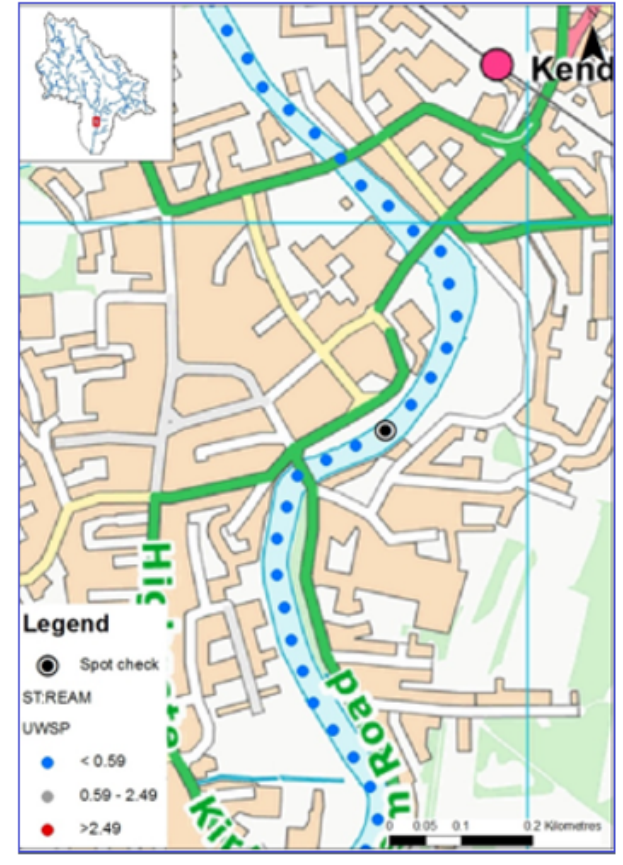

Figure 2. ST:REAM results of the River Kent near Kendal

The CAESAR-Lisflood model creates a raster grid of elevation differences $(\mathrm{m})$, with negative values indicating deposition and positive values indicating erosion.

Figure 3 shows the CAESAR-Lisflood results for the River Kent. Depositional values (blue) are negative in the output raster grid as they represent the surface elevation at the start of the simulation minus the surface elevation at the end of the simulation. Similarly, erosional values (red) are positive in the output raster grid as they represent the surface elevation at the start of the simulation minus the surface elevation at the end of the simulation. Areas without a significant change in bed elevation over the model simulation time are expected to illustrate reaches through which sediment is transported. These are identified by the 'No colour' areas in the CAESARLisflood results.

The modelled reach of the River Kent here is classified as erosion (minor) with lateral deposition which suggests that sediment will move through the system during a flood, broadly in line with the fluvial audit. 


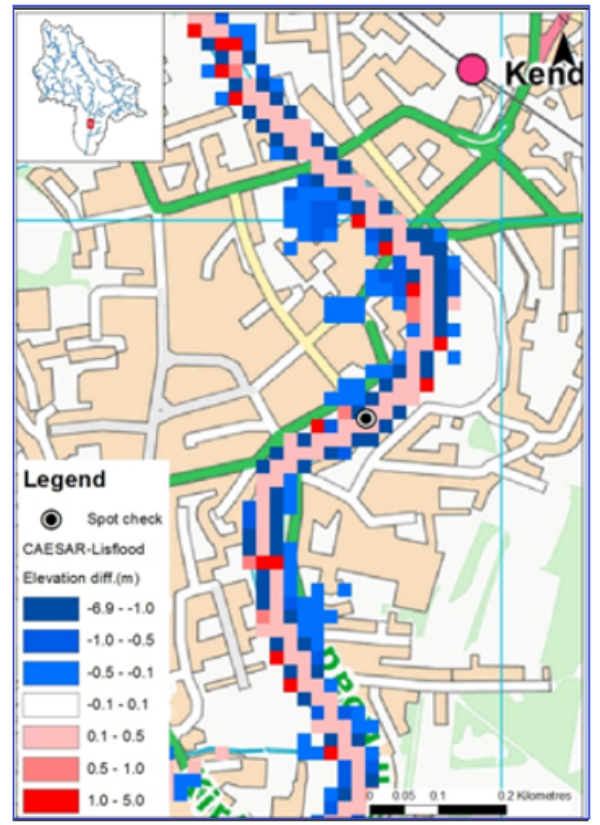

Figure 3. CAESAR-Lisflood results of the River Kent

Figure 4 shows the Half-yield method results for the River Kent. Both the Performance Factor and the Effectiveness Index from the method outputs must be examined and compared to a matrix of possible outcomes to fully interpret the results accurately.

The modelled reach is classified as depositional (Performance Factor $\mathrm{P}=0.63$ and Effectiveness Index $\mathrm{E}=$ 1). This indicates that the channel is wide (possibly incised), in-channel flows are dominant, that frequent flows are most likely to cause the deposition, and that barberm building is likely (bed raising).

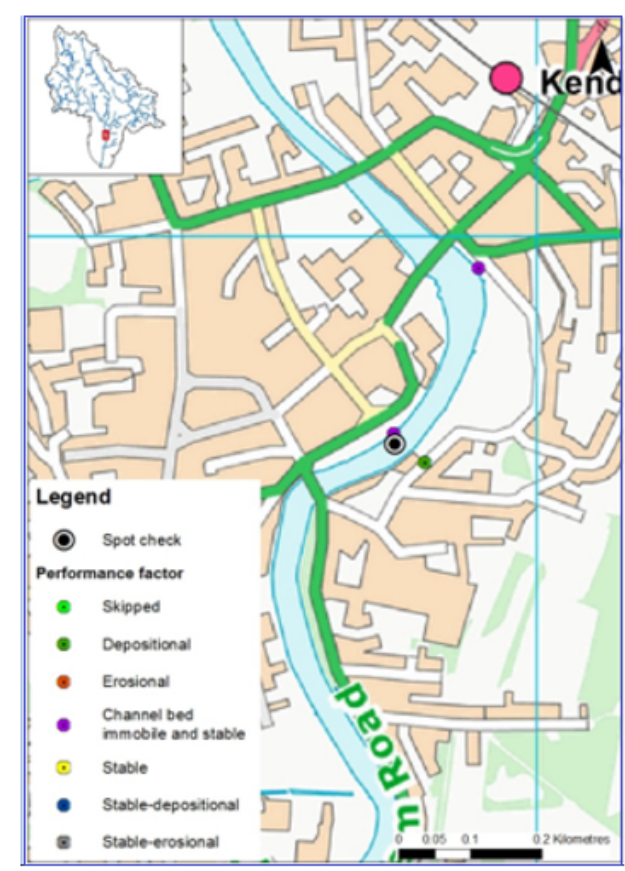

Figure 4. Half-yield results of the River Kent near Kendal
The Shear Stress Data Mining model creates zones of erosion or deposition for different probabilities of flooding. Figure 5 shows the Shear Stress Data Mining method results on the River Kent. It classified the modelled reach as depositional, in accordance with the fluvial audit.

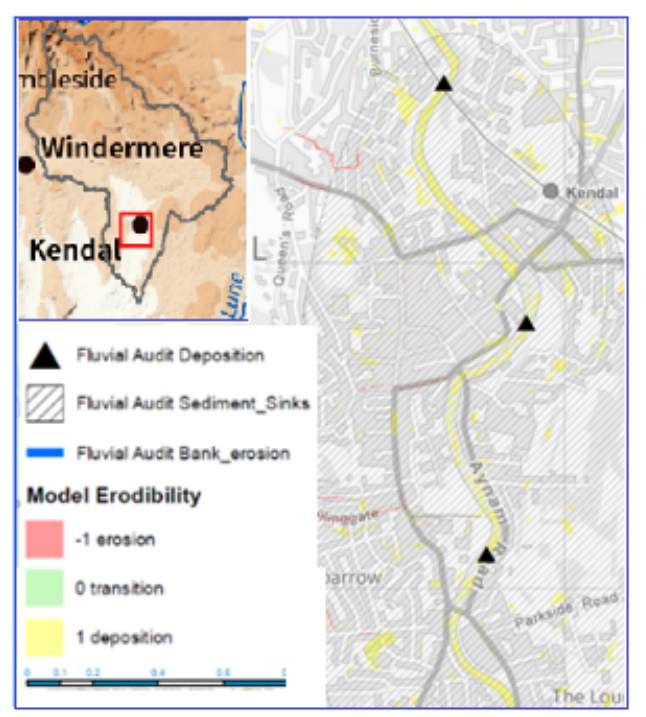

Figure 5. Shear Stress Data Mining results of the River Kent

\section{Discussion}

Each model was capable of simulating geomorphological processes and risk for certain circumstances, and each approach also had limitations.

ST:REAM is relatively practical to run nationally because the main datasets required are readily available and mainly open source (i.e. do not requiring licensing). However, ST:REAM is more accurate on higher energy rivers and less accurate on low-energy rivers, and therefore the ability to accurately model geomorphological processes is expected to vary between and across catchments. This was illustrated by the varying success rate (13-60\%) when method results were compared to fluvial audit data from low energy to high energy rivers respectively

Predicting lateral geomorphological processes and rates of erosion/deposition are also beyond the ability of the ST:REAM methodology. However, accepting these limitations, STREAM could be used to create a national scale map to show "hot spots" of erosion or deposition. This method has been used in Scotland by the Scottish Environment Protection Agency (SEPA) to create a national dataset.

In terms of modelling climate change, this could be achieved by crudely uplifting the QMED flows within the ST:REAM model. A more robust method would be to use detailed hydrological analysis at the catchment scale to provide revised QMED values that represent different climate change scenarios. This is expected to be a timeconsuming process at the national scale.

CAESAR-Lisflood showed good potential to predict geomorphological processes, providing rates of 
accumulation and net erosion/deposition at a finer spatial resolution than the other approaches. The model also incorporates sediment inputs from valley slopes and simulates lateral erosion processes which enable prediction of long-term morphological changes such as landform evolution and channel avulsion. This level of detail would be potentially very useful as an asset management planning tool.

When comparing model predictions against fluvial audit data, the results were shown to have a $50 \%$ success rate in the Kent catchment. Some of the inconsistencies were related to the coarse resolution of the LIDAR data which did not represent the current (modified) course of the channel. Modelling results were therefore offset from the existing channel location. This highlighted the essential need for model validation and sensibility checks of the results using local geomorphological knowledge, and shows that it would be beneficial to use a higher resolution DTM. CAESAR-Lisflood was more resourceintensive than other models for a given output resolution. Partly this is because not all datasets needed are readily available and required either derivation or analysis before they could be input to the model (e.g. hourly rainfall, grain size data and flow gauging). However, the level of complexity incorporated into each model is user-defined so a coarser resolution a simpler basin model could be developed with minimal data needs at the cost of reduced spatial resolution or confidence in outputs.

National scale CAESAR modelling could be possible by developing individual basin models at a catchment scale and compiling the outputs into one national dataset. However, this is expected to be resource and time intensive, requiring significant computing infrastructure, multiple teams of hydraulic modelling specialists and local geomorphological knowledge to check the model outputs.

Due to the user-defined nature of the model parametrisation and set-up, there is a risk that a different model development approach could be applied between the multiple modelling teams, leading to inconsistencies in modelling outputs between each individual basin model.

CAESAR-Lisflood can incorporate climate change by adjusting the rainfall inputs according to climate change projections using the UKCP09 Weather Generator. This has been tested in a study by Coulthard et al. (2012) in the River Swale catchment in Yorkshire and was not repeated for this research.

The Half-yield method uses the Digital River Network and RHS data, which is readily available for rivers in England and Wales. However the limited coverage and accuracy of the survey data is a key limitation of this method. The method predicted geomorphological processes well (75-100\% success rate in matching fluvial audit data in trials) when ignoring the locations where no RHS survey data is available. When accounting for the absence of the RHS survey data points, the agreement rate between model outputs and fluvial audit data reduces significantly $(38-50 \%)$. Predicting lateral geomorphological processes and rates of erosion/deposition are also beyond the ability of the HalfYield method.
In addition, since outputs are generated at individual cross-sections (with often extended reaches with no data points), the approach does not simulate spatial linkages in sediment movement between reaches. Reach-scale processes could therefore easily be missed.

It could be feasible to use the Half-Yield approach at a national scale by modelling at a catchment scale and integrating the outputs into a national level dataset. Batch processing can be undertaken, increasing the efficiency of running multiple simulations. However, the RHS survey data is sparse in some locations so until this data coverage and quality is improved is likely to result in incomplete coverage at the national scale.

Incorporating climate change into the Half-Yield method too is feasible, by manipulating the flow duration curves through the use of the Future Flows dataset (for gauged catchments) and 'change factors' (in ungauged catchments). At a national scale, it is recommended to use the 'change factors' methodology due to national scale coverage.

The Shear Stress Data Mining method is computationally efficient and uses readily available datasets. The preliminary investigation of this method within the Kent, Stour and Wharfe catchments illustrated a good potential for the model to predict geomorphological processes. Whilst the method cannot predict net erosion or deposition rates, there is the potential to identify areas of channel migration (i.e. through lateral erosion). The model is run at the national scale, so no model up-scaling is required.

\section{Creating a national pilot dataset}

A further trial was undertaken to demonstrate the potential for creating a nationwide dataset. CAESARLisflood was rejected for this study because it was resource-intensive. ST:REAM showed potential to work well in England and Wales but has already been tested for Scotland, so further testing was reserved for one of the new methods. Half-yield had good results where RHS data was available but this does not have good national coverage. The SSDM method only takes 12 hours to run for England and Wales, so this was selected for a national pilot test.

The pilot model used a range of sediment sizes, roughness values and Shield's constants, together with the three modelled flood events, to represent the broad range of hydraulic conditions likely to occur in English rivers. A total of 30 nation-wide erodibility maps were produced creating a 'scenario library' of maps. This could allow users to select the scenario most appropriate to local catchment conditions (sediment size and bed roughness).

There are limitations of using a surface water model to predict in channel erosion, as discussed previously. The variance in results would need to be explored and further validation is needed to test results in both headwaters and lowlands before any results are used for operational purposes. Further investigation into the results is needed to better understand at what spatial scale the results are more or less representative of geomorphic behaviour. 
It was not possible in this research to create a specific climate change model scenario since it aimed to reuse the existing depth and velocity data. Instead, the three rainfall scenarios $(0.1 \%, 1 \%$ and $3.33 \%$ AEP events) were used as a proxy for climate change, as this allowed an initial assessment of how increases in rainfall affect geomorphic response.

The changes in total rainfall used to derive the map outputs for the $0.1 \%, 1 \%$ and $3.33 \%$ AEP events were analysed. This found that the difference in total rainfall in the $1 \%$ to the $0.1 \%$ AEP were large $(>100 \%)$, but that the changes between $3.33 \%$ and $1 \%$ AEP rainfall totals was approximately $40 \%$ uplift. This is similar in magnitude to the projected UK rainfall intensity uplifts for 2080 (Climate Impact tool and the projected UKWIR rainfall increases (UKWIR, 2017)).

To our knowledge at the time of writing, this is the first time that data-mining a $2 \mathrm{~m}$ resolution hydraulic dataset has been created to understand the distribution of shear stresses and likely sediment erosion at the national scale. This provides, for the first time, a pilot using a $2 \mathrm{~m}$ resolution national hydraulic dataset to understand the distribution of shear stresses, and the potential for erosion in river channels across England and Wales.

\section{What this means for flood risk management}

Understanding how rivers function and react, within the wider context of its catchment, can help to develop sustainable channel management strategies, particularly those that would work with natural processes, rather than against them.

The method approaches tested could tell us more about potential for channel change and inform national strategic planning. This would help flood risk and environment management in England and Wales by giving us answers to questions like:

- Which locations are likely to need more reactive channel maintenance after extreme flows?

- Do we need to amend operational plans (incident response and channel management) so we can operate efficiently with more channel change in the future?

- Where can we optimise channel management?

- Where are the opportunities for more natural flood management and to work with natural processes?

Initial workshops were held with Environment Agency staff from flood risk management, geomorphology, risk modelling and mapping, and environment management teams. These provided opportunities to further review the results and to better understand how the Environment Agency may use national mapped data of river channel change.

At the local, catchment and national scales such data could underpin decisions for catchment management including asset and channel maintenance, location of natural flood management schemes, incident planning response in at risk locations, and for risk assessment to determine future investment needs.

Many users called for initial "hot spot" mapping to show where rivers are more likely to undergo channel changes (erosion or deposition), and users also suggested it would be useful to combine this information with other data to understand the risk of the channel change to infrastructure, land-use and communities.

At the national level, it could inform strategic plans and investment for channel maintenance over the short and long term. At a catchment level, data on river channel change would inform plans for flood risk management schemes and catchment restoration, for example where best to locate natural flood management and restore natural systems to reduce flood risk and enhance the environment. This will enable us to meet the requirements of the National Flood and Coastal Risk Management Strategy for England (Environment Agency 2019, draft) and meet the ambitions of the UK Government's 25 Year Environment Plan (Defra, 2019).

At a sub-catchment level it could target resources to the most sensitive areas, for example, where for more detailed modelling (hydrodynamic and land evolution models like CAESAR-Lisflood), to better inform reach scale channel management.

Knowing more about channel change will help flood risk management, and the natural systems, more resilient.

\section{Conclusions and next steps}

This project has tested ways to identify potential river channel change in England and Wales. These included new models and mapping techniques, developed by the research, to show likely areas of erosion and deposition.

The research showed that each of the four methods trailed each had merits and pitfalls, but that the information they could provide would support flood and environment management.

The SSDM method was used to create a scenariolibrary of mapped scenarios of river channel change, for the whole of England and Wales, in a very short space of time. This could be used to indicate areas more likely to see erosion or deposition, and to begin to understand the likely effect of climate change on channel erosion at this national scale, subject to end-users understanding the limitations of the approach.

Flood risk managers interviewed in the research agreed that national "hot-spot" or risk mapping would support strategic scale flood risk management activity like channel maintenance planning and for finding opportunities to work with natural processes.

It could also help to target local, detailed studies, creating an effective and efficient process for understanding and planning for river channel change under normal and extreme flows.

One way forward, identified in the research, could be use a combination of national strategic scale model results and available detailed hydrodynamic model results and use them where they are best applied. Other data (e.g. of land- 
use, sediment size, and flood risk) could be brought together with the modelled information into a decision support framework; an information framework that supports decision-making activities and facilitates organisational processes. A user could define their particular river management problem or operational practice and required outcome, then use the decision support framework to select the national scale method results and supporting data appropriate to their location and catchment type, to help inform that decision.

Further work is needed to test how this could be developed and used by flood risk managers. The input data would need further validation, particularly against recent field data.

The research has demonstrated how data on channel change, at a national and catchment scale, can be produced. Such information can support flood risk and environment management to plan and prepare for the future, prioritise activity to locations with greatest risk or opportunity, and deliver sustainable river maintenance and adaptation.

\section{References}

1. Bagnold, R.A. (1960). Sediment discharge and stream power - a preliminary announcement. US Geological Survey, Circular 421.

2. Bagnold, R.A. (1966). An approach to the sediment transport problem from general physics. US Geological Survey Professional Paper 422.

3. Biedenharn, D. S., Copeland, R. R., Thorne, C. R., Soar, P. J., Hey, R. D. and Watson, C. C. (2000). Effective Discharge: A Practical Guide; ERDC/CHL Technical Report TR-00-15; U.S. Army Corps of Engineers, Engineer Research \& Development Centre: Vicksburg, MS, USA, pp. 48.

4. Bizzi, S. and Lerner, D.N. (2015). The use of stream power as an indicator of channel sensitivity to erosion and deposition processes. River Research and Applications, 31, 16-27.

5. Castro, J., and Thorne, C.R., (2019). The stream evolution triangle, integrating geology, hydrology and biology. River Research and Applications, 35 (4), 315-326.

6. Coulthard, T. J., Ramirez, J., Fowler, H. J. and Glenis, V. (2012). Using the UKCP09 probabilistic scenarios to model the amplified impact of climate change on drainage basin sediment yield. Hydrological Earth System Science, 16, 4401-4416.

7. Coulthard, T.J., Neal, J.C., Bates, P.D., Ramirez, J., de Almeida, G.A.M. and Hancock, G.R. (2013). Integrating the LISFLOOD-FP 2D hydrodynamic model with the CAESAR model: implications for modelling landscape evolution. Earth Surface Processes and Landforms, 38, 1897-1906.

8. Defra (2018). A green Future: Our 25 Year Plan to Improve the Environment

9. Emmett, W.W. and Wolman, M. G. (2001). Effective discharge and gravel-bed rivers. Earth Surface

Processes \& Landforms, 26, 1369-1380.
10. Environment Agency (2014) River sediments and habitats and impacts of maintenance and capital works (SC040015).

11. Environment Agency (2014) Asset management information and data (including the 5 year FCRM asset maintenance programme)

12. Environment Agency (2019) draft National Flood and Coastal Erosion Risk Management Strategy.

13. Güneralp, I., Abad, J.D., Zolezzi, G., Hooke, J.M., (2012). Advances and challenges in meandering channels research. Geomorphology, 163-164, 1-9.

14. Komar, P.D. (1988). Sediment transport by floods. In Baker, V.R., Kochel, R.C and Patton, P.C. (eds), Flood geomorphology. New York: WileyInterscience, 97-111.

15. Kjeldson, T. (2007). The Revitalised FSR/FEH rainfall-runoff method. Centre for Ecology and Hydrology, ISBN 0903741157.

16. Klonsky, L., Vogel, R. M. (2011). Effective measures of "effective" discharge. Journal of Geology, 119, 1-14.

17. Knighton, A.D. (1999). Downstream variation in stream power. Geomorphology, 74, 297-317.

18. Lamb, R., Crossley, A. and Waller, S., 2009. A fast $2 \mathrm{~d}$ floodplain inundation model. Proceedings of the Institution of Civil Engineers: Water Management, 162.

19. Lane S.N. and Ferguson R.I., (2005) Modelling reachscale fluvial flows. Computational Fluid Dynamics: Applications in Environmental Hydraulics, John Wiley \& Sons Ltd, pp217-269.

20. Parker, C., Thorne, C.R. and Clifford, N.J. (2015). Development of ST:REAM: a reach-based stream power balance approach for predicting alluvial river channel adjustment. Earth Surface Processes and Landforms, 40, pp403-413.

21. Parry S, Barker L, Prosdocimi I, Lewis M, Hannaford J, Clemas S. 2016. Hydrological summary for the United Kingdom: December 2015. Wallingford, UK, NERC/Centre for Ecology \& Hydrology, 12pp. (CEH Project no. C04954).

22. Reid, H.E., Williams, R.D., Brierley, G.J., Coleman, S.E., Lamb, R., Rennie, C.D. and Tancock, M.J. (2018). Geomorphological effectiveness of floods to rework gravel bars: insight from hyperscale topography and hydraulic modelling. Earth Surface Processes and Landforms, 44 (2), 595-613.

23. Sear, D.A., Newson, M.D., and Thorne, C.R., (2003). Guidebook of applied fluvial geomorphology, DEFRA / Environment Agency Flood and Coastal Defence R\&D Programme Technical report, FD1914. ISBN: 0-85521-053-2.

24. Sholtes, J. S., and Bledsoe, B. P. (2016). Half-yield discharge: Process-based predictor of bankfull discharge. Journal of Hydraulic Engineering, 142(8), 04016017.

25. Shreve, R.L. (1966). Statistical law of stream numbers. Journal of Geology, 74, pp17-37. 
26. Skinner, C.J. and Coulthard, T.J. (2017). CAESARLisflood existing applications parameter listings May 2017 [Data set]. Zenodo

27. Soar, P. J. and Thorne, C. R. (2001). Channel restoration design for meandering rivers; Technical Report No. ERDC/CHL CR-01-1; Coastal and Hydraulics Laboratory, U.S. Army, Engineer Research and Development Center: Vicksburg, MS, USA.

28. Soar, P. J. and Thorne, C. R. (2011). Design discharge for river restoration. In: Simon, A., Bennett, S. J., Castro, J. M. (Eds.), Stream Restoration in Dynamic Fluvial Systems. American Geophysical Union, Washington, DC, USA, pp. 123-149.

29. Soar, P.J., Wallerstein, N.P. and Thorne, C.R. (2017). Quantifying river channel stability at the basin scale. Water, $9,133$.

30. Stroth, T. R., Bledsoe, B. P. and Nelson, P. A. (2017). Full spectrum analytical channel design with the Capacity/Supply Ratio (CSR). Water, 9, 271; doi:10.3390/w9040271.

31. Vogel, R. M., Stedinger, J. R. and Hooper, R. P. (2003). Discharge indices for water quality loads. Water Resources Research, 39(10), 1273.

32. Watts, G., Battarbee, R.W., Bloomfield, J.P., Crossman, J., Daccache, A., Durance I., Elliott, J.A., Garner, G., Hannaford, J., Hannah, D.M., Hess, T., Jackson, C.R., Kay, A.L., Kernan, M., Knox, J., Mackay, J., Monteith, D.T., Ormerod, S.J., Rance, J., Stuart, M.E., Wade, A.J., Wade, S.D., Weatherhead, K., Whitehead, P.G. and Wilby, R.L., (2015).

Climate change and water in the UK - past changes and future prospects. Progress in Physical Geography, 39, 6-28.

33. Watts, G. and Anderson, M. (eds). (2016). Water climate change impacts report card 2016 edition. Living With Environmental Change. Available from: https://nerc.ukri.org/research/partnerships/ride/lwec/r eportcards/

34. UKWIR (2017). Rainfall Intensity for Sewer Design Stage 2. REF: 17/CL/10/17. ISBN 1840578424. 